\title{
Endothelial Cysts of Adrenal Gland
}

\author{
Zafar Ali1, Hina Tariq ${ }^{2}$ and Usama Rehman 1
}

\begin{abstract}
Adrenal endothelial cyst is a rare entity which has female predilection and usually presents with abdominal pain. Smaller cysts are mostly asymptomatic and detected as incidental finding during surgery. Without biopsy, it is almost impossible to depict the nature of larger cysts as benign or malignant. Herein, we report two such cases. The first case was a 24-year female who presented with a large cyst in the abdomen. The second case was of a 35-year female, who presented with a cystic lesion of right adrenal gland. The clinical, radiological and histopathological findings are discussed. These reports highlight the salient gross, microscopic and immunohistochemical features of these cysts.
\end{abstract}

Key Words: Adrenal gland, Calcification, Endothelial cyst, Factor VIII.

\section{INTRODUCTION}

Adrenal gland cysts are rare cystic lesions that were first described by Greiselius in $1670 .{ }^{1}$ So far, more than 600 adrenal cysts have been reported in the literature. These are mostly unilateral, while upto $8-15 \%$ are bilateral. Predominantly, these are asymptomatic, nonfunctioning and benign. Clinical presentation can be both acute and chronic with devastating results due to sudden rupture of cysts or prolonged pressure effect on surrounding organs. However, abdominal or flank pain are common features. Adrenal malignancies can be purely cystic as well. In the recent era, as a result of advancements in imaging modalities (e.g. CT-Scan), these lesions can be diagnosed but these tests cannot differentiate between benign or malignant nature of the disease. On general basis, these have been further classified into four categories, which include endothelial, $(45 \%)$, pseudo (39\%), epithelial (9\%) and, parasitic cysts (7\%).

\section{CASE REPORT}

Case 1: First case was a 24-year female, who presented in the surgical outpatient department (OPD) of our hospital with the complaint of diffuse abdominal pain for the last two weeks. Initial ultrasound revealed a large cystic lesion in the abdomen. CT abdomen revealed a large cyst in the lower abdomen measuring $15 \times 12 \mathrm{~cm}$, pushing the kidney downwards and spleen upwards. Peroperatively, there was a huge cystic structure which was inseparable from adrenal gland. Approximately 1.5 liters of straw colored fluid was drawn from it. On gross

1 Department of Histopathology, Shifa International Hospital, Islamabad, Pakistan

2 Department of Histopathology, Army Medical College, Rawalpindi, Pakistan

Correspondence: Dr. Usama Rehman, Department of Histopathology, Shifa International Hospital, Islamabad, Pakistan

E-mail: usama_rhmn@yahoo.com

Received: June 27, 2018; Accepted: December 05, 2018 examination, it was a collapsed cyst measuring $8.5 \mathrm{x}$ $5.5 \mathrm{~cm}$ with attached adrenal gland at one end. Adrenal gland measured $4.0 \times 2.8 \times 0.3 \mathrm{~cm}$. On serial sectioning, cyst was multiloculated with smooth and shiny inner surfaces. Few firm areas were also present.

Microscopic examination of the cyst wall revealed flattened endothelial lining with underlying compressed adrenal cortical parenchyma (Figures $1 \mathrm{~A}$ and $\mathrm{B}$ ). Focal areas of hemorrhage and calcification were also seen. Adrenal gland sections showed no significant pathology. On immunohistochemistry, Factor VIII strongly highlighted the cytoplasm of vascular endothelial cells, which were negative on calretinin and EMA stains. She was discharged on sixth postoperative day. Pain was resolved and she did not require any special follow-up.

Case 2: A 35-year female presented with abdominal discomfort and distention. CT scan revealed a large well-defined, homogeneous mass with few peripheral calcifications in the right hypochondrium, compressing and displacing the abdominal structures. Laparoscopic adrenalectomy was done. Histopathological gross examination showed a large tan brown cystic structure, weighing 1,464 grams and measuring $19 \times 14 \times 7 \mathrm{~cm}$. A small knot of prolene suture was placed to highlight adrenal gland which measured $2.5 \times 1 \times 0.5 \mathrm{~cm}$. On opening, the cyst was unilocular and contained dirty yellowish material. The internal surface was smooth with maximum wall thickness of $0.2 \mathrm{~cm}$.

Microscopic sections of cyst wall showed partly intact endothelial cells. There was compressed adrenal gland parenchyma in the wall, along with extensive dystrophic calcification (Figure 1C). On immunohistochemistry, this epithelial lining was positive for Factor VIII (Figure 1D). She was discharged after four days. She is alive and doing well.

\section{DISCUSSION}

Adrenal cysts are a heterogeneous group of lesions. In autopsy series, their incidence has been reported as 


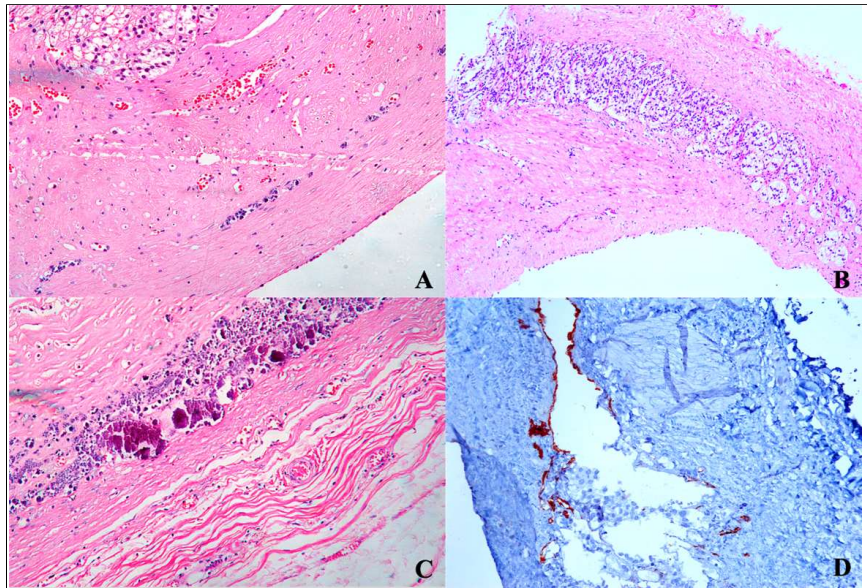

Figure 1: (A) Histologic section of the first case showing a cyst lined by flattened cells (hematoxylin and eosin, x 100). (B) Cyst wall histologic section showing compressed adrenal gland tissue in the wall of the cyst in the first case (Hematoxylin eosin, x 100). (C) Foci of dystrophic calcification in the cyst wall in case 2 (H and E, x 100). (D) Factor VIII immunostain highlighting the lining epithelium of the cyst (Immunostain, $x$ 100).

$0.06 \%$. As far as the pathogenesis of vascular cysts is concerned, various theories have favoured origin from pre-existing vascular hamartoma, ectasia of lymphatic channels or secondary to intraparenchymal hemorrhage.2 Foster in 1966, divided adrenal cysts into 4 main types: (a) endothelial cysts, (b) pseudocysts, (c) epithelial cysts and (d) parasitic cysts. ${ }^{3}$

Adrenal cysts occur in all age groups but are more common in the third and sixth decades. The male to female ratio is $1: 3$. The size of cysts ranges from several millimeters to more than $20 \mathrm{~cm}$ in diameter. They can be unilocular or multilocular. Most of them are solitary, with equal involvement of both adrenal glands. In most of the patients, abdominal pain is the presenting feature, followed by their incidental defection. Although the cystic nature of these lesions is demonstrated on ultrasonographic and CT scans, their histologic type cannot be predicted. ${ }^{4}$

The adrenal vascular cysts are known to have calcifications in $15 \%$ to $30 \%$ of cases, as in one of these cases. ${ }^{5}$ On gross examination, endothelial cysts are well circumscribed and surrounded by a capsule, with size ranging from $1.4 \mathrm{~cm}$ to $33 \mathrm{~cm}$. Microscopically, endothelial cysts comprise of fibrous wall with patchy lining by flattened cells resembling normal endothelium. These cells are positive for endothelial cell markers i.e podoplanin, FLI1, CD31 and factor VIII, confirming their endothelial nature. 6 On the other hand, pseudocysts, typically lack any lining epithelium. Clinically, differential diagnosis of vascular adrenal cysts include cystically degenerated adrenal neoplasms, such as pheochromocytoma, adrenal cortical adenoma, adrenal cortical carcinoma or rarely metastatic carcinoma. Detailed grossing including close examination of cystic contents with meticulous sampling of the wall can help reaching a conclusive diagnosis. ${ }^{7}$

In summary, cystic adrenal lesions are uncommon and can range from benign cysts to cystic primary adrenal tumors. The laparoscopic enucleation is the treatment of choice. A thorough examination is mandatory for evaluation of these lesions.

\section{REFERENCES}

1. Amarillo HA, Bruzoni M, Loto M, Castagneto GH, Mihura ME. Hemorrhagic adrenal pseudocyst: Laparoscopic treatment. Surg Endosc 2004; 18:1539.

2. Chetty R, Dada MA. Focal nodular hyperplasia of the liver coexisting with an adrenal pseudocyst. S Afr J Surg 1998; 36: 82-3.

3. Khan MR, Ajmal S, Saleem T. Giant adrenal endothelial cyst associated with acute and chronic morbidity in a young female: A case report. Cases J 2009; 2:8841.

4. Otal P, Escourrou G, Mazerolles C, Janne d'Othee B, Mezghani S, Musso $\mathrm{S}$, et al. Imaging features of uncommon adrenal masses with histopathologic correlation. Radiographics 1999; 19:569-81.

5. Abeshouse GA, Goldstein RB, Abeshouse BS. Adrenal cysts: Review of the literature and report of three cases. J Urol 1959; 81:711-9.

6. Erickson LA, Lloyd RV, Hartman R, Thompson G. Cystic adrenal neoplasms. Cancer 2004; 101:1537-44.

7. Nerli RB, Guntaka A, Devaraju S, Patil S, Hiremath MB. Adrenal cysts: Our laparoscopic experience. J Minim Access Surg 2012; 8:145-8. 